\title{
Preparation and electrochemical characteristics of spherical spinel cathode powders via an ultrasonic spray pyrolysis process
}

\author{
Chung-Hsin $\mathrm{Lu}^{\mathrm{a}, *}$, Tai-Yuan $\mathrm{Wu}^{\mathrm{a}}$, Hung-Chun $\mathrm{Wu}^{\mathrm{b}}$, Mo-Hua Yang ${ }^{\mathrm{b}}$, Zheng-Zhao Guo ${ }^{\mathrm{b}}$, Izumi Taniguchi ${ }^{\mathrm{c}}$ \\ a Department of Chemical Engineering, National Taiwan University, Taipei, Taiwan \\ ${ }^{\mathrm{b}}$ Materials Research Laboratory, Industrial Technology Research Institute, Taiwan

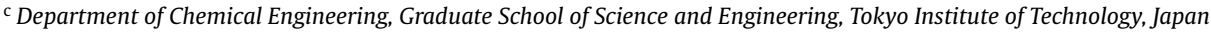

\section{A R T I C L E I N F O}

\section{Article history:}

Received 17 January 2007

Received in revised form 11 April 2008

Accepted 16 May 2008

\section{Keywords:}

Lithium ion battery

Cathode materials

Spray pyrolysis

Porosity

Spinel structure

\begin{abstract}
A B S T R A C T
$\mathrm{Li}_{1.03} \mathrm{Co}_{0.15} \mathrm{Mn}_{1.82} \mathrm{O}_{4}$ powders as cathode materials used in lithium-ion battery were synthesized using an ultrasonic spray pyrolysis process. The prepared powders were heated at $750^{\circ} \mathrm{C}$ for different heating durations. As the heating time increased, the crystallinity of the powders significantly enhanced. The nanometered primary particles were aggregated into sphere-like secondary particles with a porous structure. The surface area of the heated samples decreased with an increase in the heating time. After the characteristics of electrochemical performance, the powders heated for $4 \mathrm{~h}$ exhibited improved properties. When the discharge rate was $60 \mathrm{C}$, this sample revealed high capacity retention which was $87 \%$ with the reference of $0.1 \mathrm{C}$. According to the results of high C-rate tests, the electrochemical characteristic of the prepared $\mathrm{Li}_{1.03} \mathrm{Co}_{0.15} \mathrm{Mn}_{1.82} \mathrm{O}_{4}$ powders were found to depend on not only the crystallinity but also the surface area. For preparing cathode materials with good rate capability, the crystallinity and surface area of the materials need to be well controlled.
\end{abstract}

(C) 2008 Elsevier B.V. All rights reserved.

\section{Introduction}

The rapid development of portable electronics and electric vehicles significantly increases the demands for new energy sources. The low cost, environment friendly and high energy density lithium-ion battery is the promising portable energy source in the next-generation. In lithium-ion batteries the cathode materials play a very important role. The ideal cathode materials should have high capacity, reliability and cycle life. Spinel-structured lithium manganese oxide $\mathrm{LiMn}_{2} \mathrm{O}_{4}$ is considered to be an attractive cathode material because of low cost and acceptable environmental characteristics [1-5]. However, $\mathrm{LiMn}_{2} \mathrm{O}_{4}$ exhibit significant capacity fading during charge/discharge cycle due to fracture of structure [6-8], decomposition of the electrolyte at high-voltage region, and the dissolution of $\mathrm{Mn}^{3+}$ ions into the electrolyte [5].

Many researchers have paid much attention to suppress the capacity loss of $\mathrm{LiMn}_{2} \mathrm{O}_{4}$ during cycling $[1,7,9]$. Different studies have focused on the partial substitution of monovalent and multivalent cations for manganese ions. The spinel compounds $\mathrm{LiCo}_{y} \mathrm{Mn}_{2-y} \mathrm{O}_{4}$ prepared by solid-state reactions was found to exhibit significantly improved cycle performance [10,11]. This

\footnotetext{
* Corresponding author. Tel.: +886 2 23651428; fax: +886223651428.

E-mail address: chlu@ntu.edu.tw (C.-H. Lu).
}

material has been reported to have relatively strong metal-oxygen bonding in the substituted spinel structure [10-12].

Spinel-structured lithium cobalt manganese oxide is usually prepared by the solid-state reactions, which involves the mechanical mixing of oxides and/or carbonates. These reactions usually require prolonged heating processes and repeated grinding. In this kind of processes, it is difficult to control the morphology and the particle size of the products. In recent years, considerable interest has been paid ob liquid-phase processes for adjusting the morphology, bulk density, and microstructure of the obtained powders [13-16]. Within these processes, the ultrasonic spray pyrolysis process is regarded as an effective technique because it can shorten the reaction time, and produce particles with uniform morphology and homogeneous compositional distribution [17-21]. In the above process, the droplets from the starting solution are generated by ultrasonic wave and are subsequently transported by the carrier gas to a heated zone. During the heating process, the solvent evaporated and atomic arrangement of constituent species took place. After the heating process, the as-prepared particles will aggregate into a spherical shape with a porous structure. This process can control the particle size of obtained powders to range from micrometer to nanometer. This unique morphology of the resulting powders makes the spray pyrolysis become widely used in synthesizing ceramic materials [18-21].

In this paper, spinel-structured $\mathrm{Li}_{1.03} \mathrm{Co}_{0.15} \mathrm{Mn}_{1.82} \mathrm{O}_{4}$ powders were prepared by the ultrasonic spray pyrolysis method. The as- 
prepared particles were heated for different heating time. The crystallite sizes, particle sizes and charge-discharge performance of the heated powders were investigated. The relation between the electrochemical characteristic and particulate properties were also discussed in this study.

\section{Experimental}

$\mathrm{LiNO}_{3}, \mathrm{Mn}\left(\mathrm{NO}_{3}\right)_{2} \cdot 6 \mathrm{H}_{2} \mathrm{O}$ and $\mathrm{Co}\left(\mathrm{NO}_{3}\right)_{2}$ were used as the starting materials. The metal nitrates were measured as the composition of stoichiometric amounts and dissolved in distilled water. The concentration of the total metal nitrate was $0.9 \mathrm{~mol} \mathrm{dm}^{-3}$. The mist of aqueous nitrate solution was generated by an ultrasonic vibrator, and then was introduced into an electrical furnace for drying and pyrolysis. The laminar flow aerosol reactor used in the present study was a quartz tube of $90 \mathrm{~mm}$ inner diameter and $1.86 \mathrm{~m}$ length, which was inserted into a horizontal electric furnace. We have added the above statement in the section of experimental. The flow rate of air for carrying the mist was $2 \mathrm{dm}^{3} \mathrm{~min}^{-1}$. The mist remained inside the reaction tube for approximately $4.8 \mathrm{~min}$ and was pyrolyzed at $800^{\circ} \mathrm{C}$. As-prepared powders were collected using an electrostatic precipitator. The production rate of the sample was $0.5 \mathrm{~g} \mathrm{~h}^{-1}$.

The as-prepared powders were heated at $750{ }^{\circ} \mathrm{C}$ for different durations. The sample was quenched in the furnace when the temperature reached $750{ }^{\circ} \mathrm{C}$ (Sample A). Some of the as-prepared powders were heated at $750^{\circ} \mathrm{C}$ for $1 \mathrm{~h}$ (Sample B), $4 \mathrm{~h}$ (Sample C) and $8 \mathrm{~h}$ (Sample D) in air. The heating rate was $2^{\circ} \mathrm{Cmin}^{-1}$. The morphology of the resulting particles was analyzed using the field-emission scanning electron microscope (FE-SEM, Hitachi, S-800). The phase of the samples was examined by X-ray diffraction (XRD, Phillips, PW1700). The surface area of powders was determined by BET method using nitrogen.

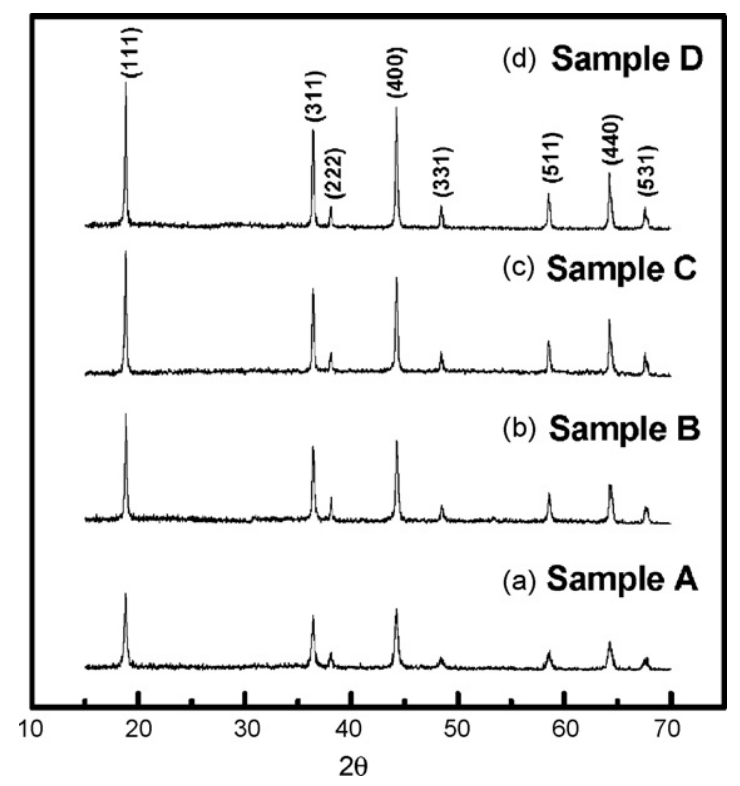

Fig. 1. XRD patterns for $\mathrm{Li}_{1.03} \mathrm{Co}_{0.15} \mathrm{Mn}_{1.82} \mathrm{O}_{4}$ powders via the spray pyrolysis process by heating at $750^{\circ} \mathrm{C}$ in air for different time.
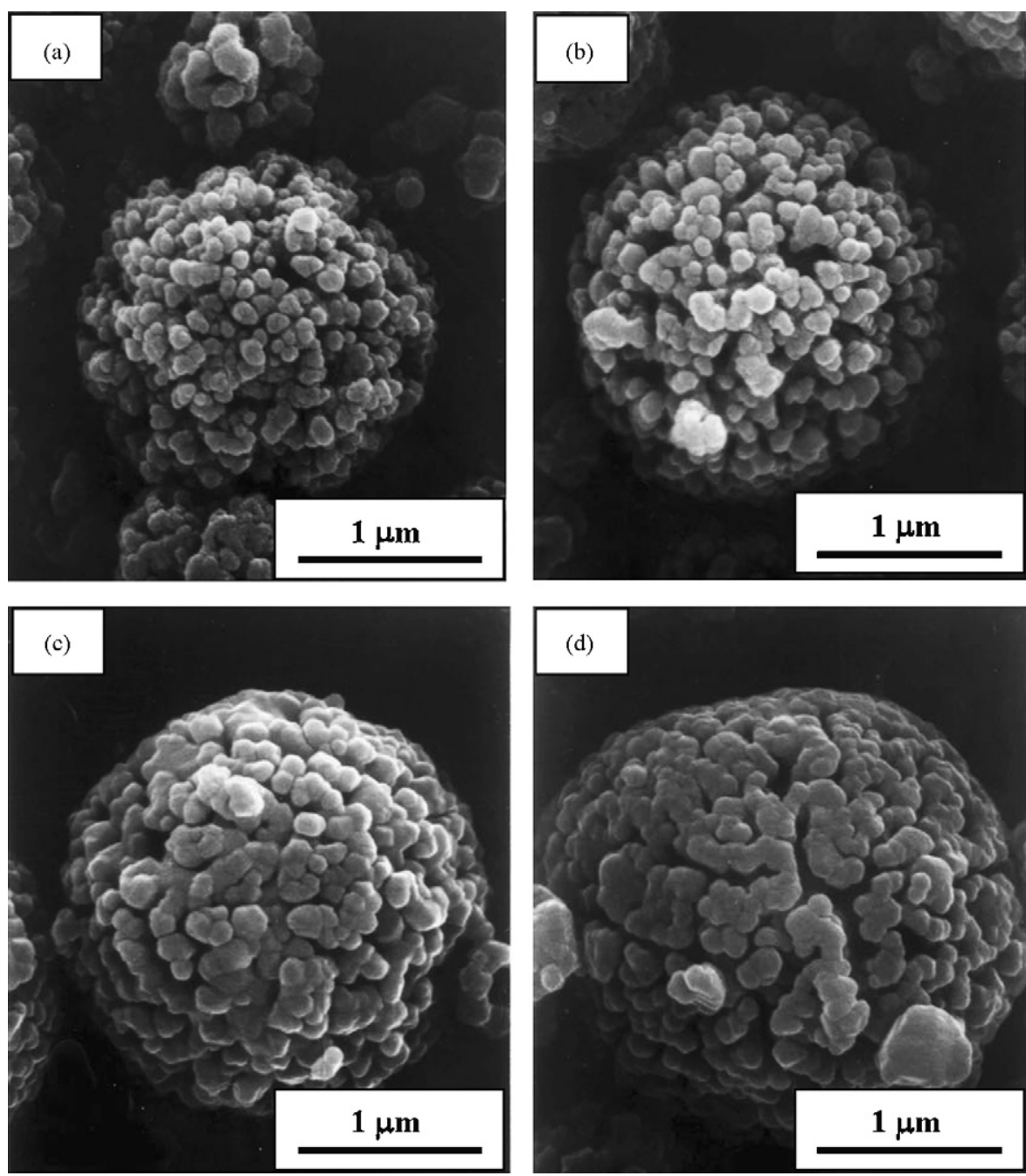

Fig. 2. SEM photographs for $\mathrm{Li}_{1.03} \mathrm{Co}_{0.15} \mathrm{Mn}_{1.82} \mathrm{O}_{4}$ powders after heating at $750{ }^{\circ} \mathrm{C}$ (a) for quenched, (b) for $1 \mathrm{~h}$, (c) for $4 \mathrm{~h}$ and (d) for $8 \mathrm{~h}$. 
The electrochemical properties of the heated samples were carried out using lithium coin-type cells (CR2032). For preparing the cathode electrodes, the spinel powders were mixed with poly-vinylidene fluoride (PVdF), graphite and carbon black in a weight ratio 78:10:6:6. The $n$-methylpyrrolidone (NMP) was used as the solvent to form the slurry. The mixed slurry was coated on a $20-\mu \mathrm{m}$-thick $\mathrm{Al}$ foil. The electrolyte was $1 \mathrm{M} \mathrm{LiPF}_{6}$ in a 1:2 mixture of ethylene carbonate (EC) and dimethylcarbonate (DMC) by volume. The cell properties were measured galvanostatically over a potential range between $3.0 \mathrm{~V}$ and $4.4 \mathrm{~V}$ at room temperature. The charge/discharge rate at $0.1 \mathrm{C}$ was fixed at $10.5 \mathrm{mAg}^{-1}$.

\section{Results and discussions}

\subsection{Structural and microstructural analysis of prepared $\mathrm{Li}_{1.03} \mathrm{Co}_{0.15} \mathrm{Mn}_{1.82} \mathrm{O}_{4}$ powders}

Fig. 1 illustrates the XRD pattern of $\mathrm{Li}_{1.03} \mathrm{Co}_{0.15} \mathrm{Mn}_{1.82} \mathrm{O}_{4}$ powders synthesized by the spray pyrolysis process followed by heating at $750{ }^{\circ} \mathrm{C}$ for different durations. All the samples in this XRD pattern were identified as a single-phase spinel with a space group of $F d \overline{3} m$ (No. 227). The as-quenched sample (Sample A) had broad diffraction peaks with weak diffraction intensities. As the duration of heating time increased, the diffraction peaks became narrow and the intensities increased. This indicates that extending the heating time enhanced the crystallinity. The crystallite sizes of heated $\mathrm{Li}_{1.03} \mathrm{Co}_{0.15} \mathrm{Mn}_{1.82} \mathrm{O}_{4}$ powders were calculated by Debye-Scherrer equation. The crystallite sizes of samples quenched and heated for $1 \mathrm{~h}, 4 \mathrm{~h}$ and $8 \mathrm{~h}$ (Samples A-D) were $23.3 \mathrm{~nm}, 39.6 \mathrm{~nm}, 52 \mathrm{~nm}$ and $58.9 \mathrm{~nm}$, respectively. This shows that crystallite size increases as the heating time increases.

Fig. 2 shows the FE-SEM photographs of $\mathrm{Li}_{1.03} \mathrm{Co}_{0.15} \mathrm{Mn}_{1.82} \mathrm{O}_{4}$ powders. It is observed that spherical particles were successfully prepared by the spray pyrolysis process. The as-prepared powders exhibited spherical-like secondary particles which were formed by the aggregation of nanometered primary particles. Therefore the derived powders showed a porous structure. After heating at $750^{\circ} \mathrm{C}$, all samples remained their spherical morphology and did not collapse. From Fig. 2 it can be observed that when prolonging the heating time, the sizes of the primary particles increased and the secondary particles became dense after heating at $750{ }^{\circ} \mathrm{C}$. Therefore, the surface area of particles decreased.

\subsection{Particulate properties of prepared $\mathrm{Li}_{1.03} \mathrm{Co}_{0.15} \mathrm{Mn}_{1.82} \mathrm{O}_{4}$ powders}

The powders heated for various time were analyzed by the BET method. The summarized results are showed in Fig. 3. As seen in this figure, the crystallinity increased with prolonging the heating time. On the contrary, the surface area reduced when the heating time increased. From the sample quenched to the one heated for $8 \mathrm{~h}$ (Samples A-D), the values of surface area decreased from $9.35 \mathrm{~m}^{2} \mathrm{~g}^{-1}$ to $4.01 \mathrm{~m}^{2} \mathrm{~g}^{-1}$.

\subsection{Electrochemical analysis of $\mathrm{Li}_{1.03} \mathrm{Co}_{0.15} \mathrm{Mn}_{1.82} \mathrm{O}_{4}$}

Fig. 4 illustrates the first cycle of charge and discharge curves at the $0.1 \mathrm{C}$ rate at room temperature for the as-prepared $\mathrm{Li}_{1.03} \mathrm{Co}_{0.15} \mathrm{Mn}_{1.82} \mathrm{O}_{4}$ powders heated for different time. All samples showed a two-stage discharge plateau. This is due to the phase transition from two-phase region with cubic spinel structure to an ordered configuration of lithium ions on the half of the tetrahedral 8a sites [18-22]. As the heating time increased, the discharge capacity increased. The capacities of Samples A-D are $98 \mathrm{mAh} \mathrm{g}^{-1}$, $107 \mathrm{mAh} \mathrm{g}^{-1}, 108 \mathrm{mAh}^{-1}$ and $113 \mathrm{mAh} \mathrm{g}^{-1}$, respectively (also see Table 1 ). This is due to the increase in the crystallinity as shown in Fig. 1. On the other hand, it also showed a trend of decrease in the irreversible capacity. The powders of Sample D had the highest

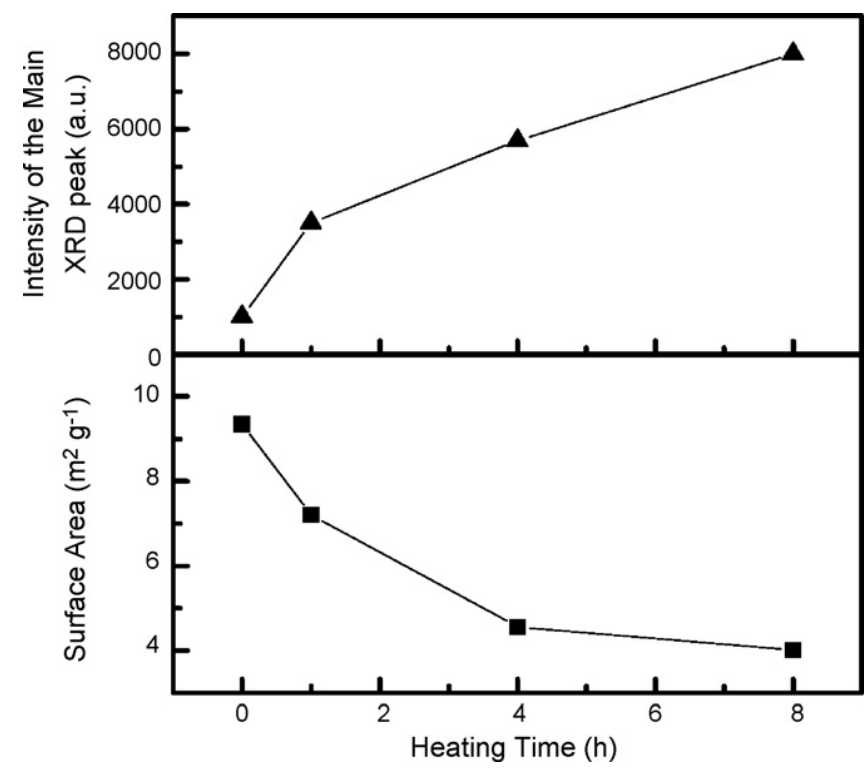

Fig. 3. The relative intensity of the main diffraction peak, surface area, and porosity of $\mathrm{Li}_{1.03} \mathrm{Co}_{0.15} \mathrm{Mn}_{1.82} \mathrm{O}_{4}$ powders heating for various time.

capacity because of the improved crystallinity. For all the samples the irreversible capacity was below $10 \%$. The above results indicated that spinel-structured $\mathrm{Li}_{1.03} \mathrm{Co}_{0.15} \mathrm{Mn}_{1.82} \mathrm{O}_{4}$ powders can be synthesized by the ultrasonic spray pyrolysis process, and after the heat treatment the as-prepared powders showed an improved electrochemical properties rather than the quenched sample. Comparing

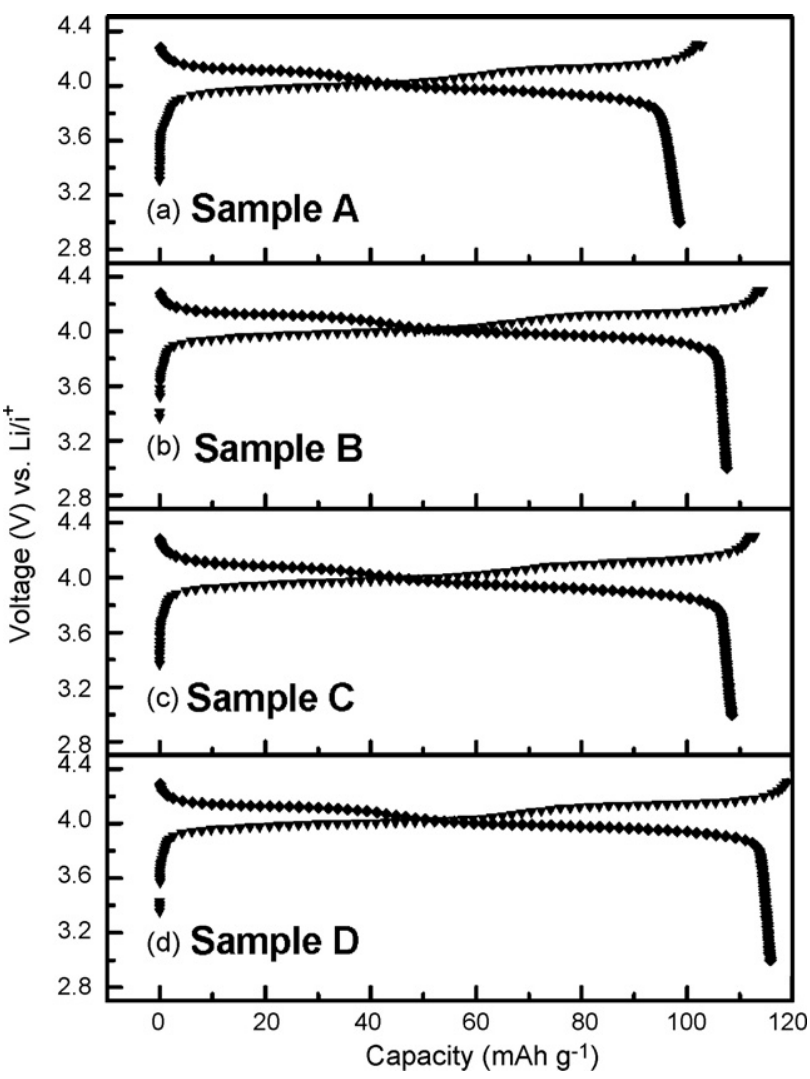

Fig. 4. Charge and discharge curves at first cycle of the $750^{\circ} \mathrm{C}$-heating $\mathrm{Li}_{1.03} \mathrm{Co}_{0.15} \mathrm{Mn}_{1.82} \mathrm{O}_{4}$ powders for various heating time, (a) for quenched, (b) for $1 \mathrm{~h}$, (c) for $4 \mathrm{~h}$ and (d) for $8 \mathrm{~h}$. 
Table 1

Electrochemical properties of $\mathrm{Li}_{1.03} \mathrm{Co}_{0.15} \mathrm{Mn}_{1.82} \mathrm{O}_{4}$ powders

\begin{tabular}{|c|c|c|c|c|}
\hline Sample & A & B & $\mathrm{C}$ & $\mathrm{D}$ \\
\hline Heating condition & Quenched at $750^{\circ} \mathrm{C}$ & Heated at $750^{\circ} \mathrm{C}, 1 \mathrm{~h}$ & Heated at $750^{\circ} \mathrm{C}, 4 \mathrm{~h}$ & Heated at $750^{\circ} \mathrm{C}, 8 \mathrm{~h}$ \\
\hline Discharge capacity at 1 st cycle $\left(\mathrm{mAh}^{-1}\right)$ & 98 & 107 & 108 & 113 \\
\hline Irreversible capacity at 1 st cycle (\%) & 6.53 & 4.18 & 3.80 & 4.45 \\
\hline Capacity retention at $60 \mathrm{C}$-rate (\%) & $\sim 30$ & $\sim 69$ & $\sim 87$ & $\sim 50$ \\
\hline
\end{tabular}

with the spinel cathode materials prepared by the solid-state route, it reveals the similar discharge capacity [22-24].

Fig. 5 illustrates the charge-discharge curves of $\mathrm{Li}_{1.03} \mathrm{Co}_{0.15} \mathrm{Mn}_{1.82} \mathrm{O}_{4}$ materials at different C-rates. As observed in Fig. 5, all samples showed complete discharge curves with a voltage plateau at $3.9 \mathrm{~V}$ during the low C-rate tests. However, sample A showed poor capacity retention at high discharge rates. When discharging at the rate of $60 \mathrm{C}$, the capacity retention was merely $32 \%$ with respect to the capacity at $0.1 \mathrm{C}$ and the discharge plateau almost disappeared. This is due to its insufficient crystallinity in the powders. In Fig. 5(c) the discharge curve of Sample $C$ showed a complete plateau that exhibited good electrochemical performance at the rate of $60 \mathrm{C}$. On the other hand, for Sample $\mathrm{D}$ with high crystallinity did not show enough capacity retention compared with Sample $C$ when discharging at the high C-rates. The discharge plateau of $60 \mathrm{C}$-rate was not complete.

Fig. 6 summarizes the charge-discharge capacity retention at different C-rate tests with respect to the capacity at $0.1 \mathrm{C}$. The retention behavior is significantly difference when the prepared materials were charged/discharged during low and high C-rate tests. Under the conditions of the slow rate of charging and discharging $(\leqq 4 \mathrm{C})$, four samples showed similarly high capacity retention which was around 95\%. However, increasing the C-rate resulted in decreasing the capacity retention, and different samples showed a greatly different performance. At 60 C-rate discharging, Sample A showed poor capacity retention which was only $30 \%$. The

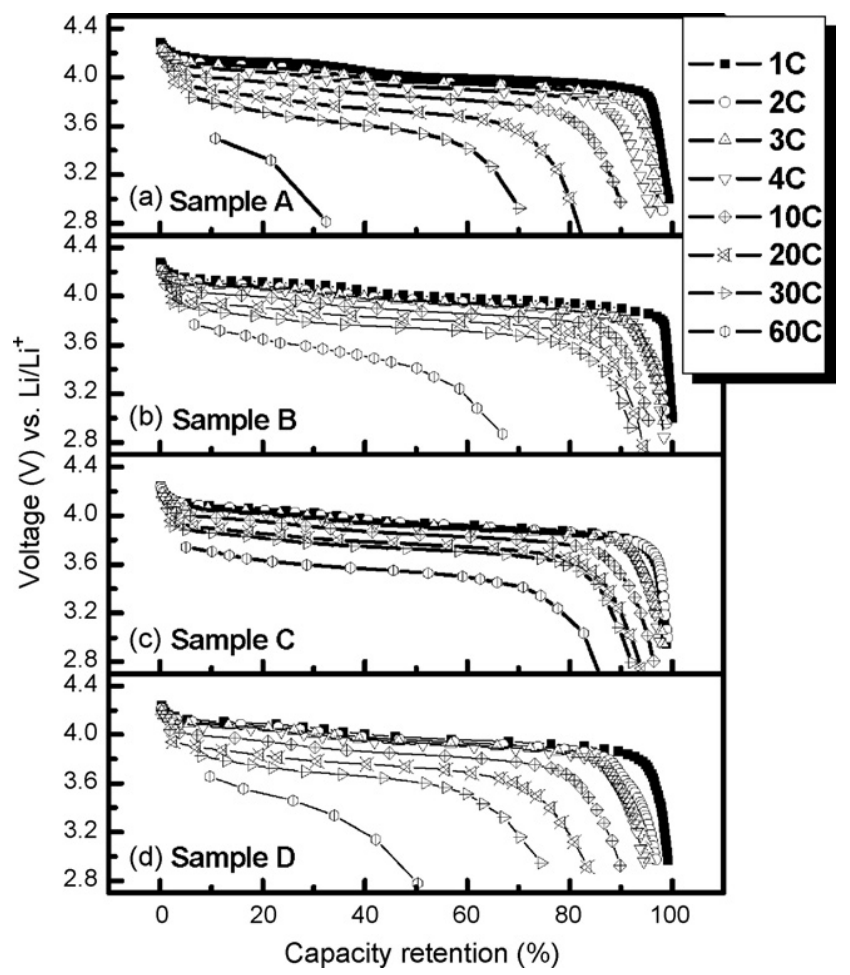

Fig. 5. Discharge curves at different $C$-rates of $\mathrm{Li}_{1.03} \mathrm{Co}_{0.15} \mathrm{Mn}_{1.82} \mathrm{O}_{4}$ powders with the related of capacity retention with $0.1 \mathrm{C}$ as the reference. rate capability of Sample D also decreased significantly. The retention was $50 \%$ when discharging at 60 C-rate (Table 1). Although Sample D had the highest discharge capacity of $113 \mathrm{mAh}^{-1}$ at the first cycle (Fig. 4(d)), the capacity retention was low at high charge-discharge rate. For Sample $C$, capacity retention was near $90 \%$ at high C-rate tests. Even at $60 \mathrm{C}$ rate it still had $87 \%$. Comparing with other high C-rate tests $[25,26]$, the reported spinel-structured materials showed a low retention which was less than $50 \%$ at a rate $<10 \mathrm{C}$.

As the heating time increased, the crystallinity of prepared powders increased. It resulted in a perfect crystal structure. Therefore when the heating time increased, the capacity retention at high Crates increased. However, when the heating time is up to $8 \mathrm{~h}$, the capacity retention decreased. This is because the decrease in the surface area of powders. The sample heated for $8 \mathrm{~h}$ had larger primary particles than others, resulting in less pores and less surface area. For the charge/discharge process, transferring of lithium ions depends on the covered area of electrolyte on the electrode surface. If the electrolyte can distribute uniformly on the electrode surface, it can offer more paths of intercalation/deintercalation process and show better rate capability. In this case Sample D had the largest discharge capacity, but the poor capacity retention at $60 \mathrm{C}$ rate. This is because the requirement of the fast intercalation and deintercalation of lithium ions within the interface. Although Samples A and B showed larger surface area, the crystallinity was insufficient, led a poor sustaining at high C-rate tests. These effects may be significant during the charge-discharge at high $\mathrm{C}$-rates.

After charging-discharging at the $60 \mathrm{C}$ rate, all the samples were tested at $1 \mathrm{C}$ rate again. Four samples exhibited capacity retention which was around $90 \%$. The results indicated that all samples revealed the performance close to the first cycle. Therefore, the spinel-structured cathode materials prepared by the ultrasonic

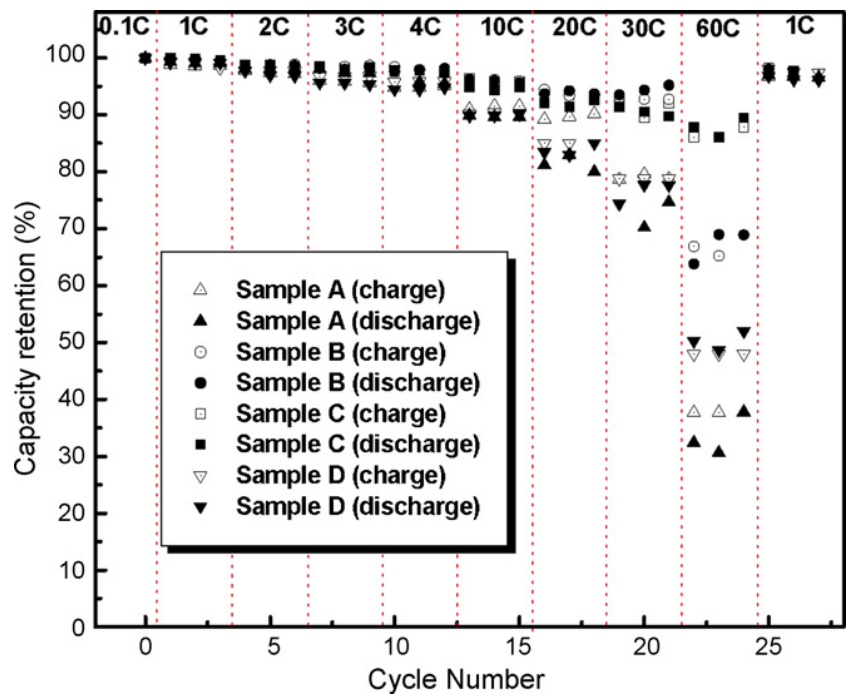

Fig. 6. Relation between the capacity retention and the cycle number of the $\mathrm{Li}_{1.03} \mathrm{Co}_{0.15} \mathrm{Mn}_{1.82} \mathrm{O}_{4}$ powders in different C-rate tests with $0.1 \mathrm{C}$ as the reference. The hollow points show the capacity retention of charge and the filled points show the one of discharge. 
spray pyrolysis process can have rigid crystal structure. They could sustain high rate charge/discharge tests without the collapse of their structures.

From the above results, prolonging the heating time can improve the crystallinity of the powders, thereby resulting in an increase in the discharge capacity. However, extended heating time also caused the surface area to decrease, thereby affecting the rate capability. The crystallinity and the surface area are always the complementary factors and in competition during the synthesis. After the heat treatment for $4 \mathrm{~h}$, the derived powder can have improved properties due to the combination of proper crystallinity and surface area.

\section{Conclusions}

Spinel-structured $\mathrm{Li}_{1.03} \mathrm{Co}_{0.15} \mathrm{Mn}_{1.82} \mathrm{O}_{4}$ cathode materials with porous structure and nanoscaled primary particles were synthesized successfully by the ultrasonic spray pyrolysis process. After heating the as-prepared precursors at $750^{\circ} \mathrm{C}$, the powders with a single spinel phase were obtained. The synthesized powders had a spherical shape which was formed by nanoscaled primary particles. Increasing the heating resulted in a decrease in surface area without changing the morphology. $\mathrm{Li}_{1.03} \mathrm{Co}_{0.15} \mathrm{Mn}_{1.82} \mathrm{O}_{4}$ cathode materials heated for $4 \mathrm{~h}$ showed a relatively improved performance at high C-rate tests. It showed high capacity retention which was $87 \%$ at the $60 \mathrm{C}$-rate with respect to the capacity at $0.1 \mathrm{C}$ rate. For obtaining good electrochemical performance at high C-rates, the crystallinity as well as the surface area of the particles need to be well controlled.

\section{References}

[1] H. Huang, P.G. Bruce, J. Power Sources 54 (1995) 52.

[2] T. Ohzuku, M. Kitagawa, T. Hirai, J. Electrochem. Soc. 137 (1990) 769.

[3] J.M. Tarascon, D. Guyomard, Electrochim. Acta 38 (1993) 1221.

[4] G. Pistoia, G. Wang, C. Wang, Solid State Ionics 58 (1992) 285.

[5] J.M. Tarascon, E. Wang, F.K. Shokoohi, W.R. McKinnon, S. Colson, J. Electrochem. Soc. 138 (1991) 2859.

[6] J.M. Tarascon, W.R. McKinnon, F. Coowar, T.N. Bowmer, G. Amatucci, D. Guyomard, J. Electrochem. Soc. 141 (1994) 1421

[7] R.J. Gummow, A. de Kock, M.M. Thackeray, Solid State Ionics 69 (1994) 59.

[8] Y. Xia, H. Noguchi, M. Yoshio, J. Solid State Chem. 119 (1995) 216.

[9] R. Bittihn, R. Herr, D. Hoge, J. Power Sources 43/44 (1993) 223.

[10] L. Guohua, H. Ikuta, T. Uchida, M. Wakihara, J. Electrochem. Soc. 143 (1996) 178.

[11] D. Song, H. Ikuta, T. Uchida, M. Wakihara, Solid State Ionics 117 (1999) 151.

[12] M. Wakihara, G. Li, H. Ikuta, in: M. Wakihara, O. Yamamoto (Eds.), Lithium Ion Batteries, Kodansha-VCH, 1998, p. 26

[13] X. Qiu, X. Sun, W. Shen, N. Chen, Solid State Ionics 93 (1997) 335

[14] H. Huang, P.G. Bruce, J. Electrochem. Soc. 141 (1994) L106.

[15] N. Amdouni, F. Gendron, A. Mauger, H. Zarrouk, C.M. Julien, Mater. Sci. Eng. B 129 (2006) 64.

[16] D. Im, A. Manthiram, J. Electrochem. Soc. 150 (2003) A742.

[17] G.L. Messing, S.C. Zhang, G.V. Javanthi, J. Am. Ceram. Soc. 76 (1993) 2707

[18] I. Taniguchi, D. Song, M. Wakihara, J. Power Sources 109 (2002) 333.

[19] I. Taniguchi, C.K. Lim, D. Song, M. Wakihara, Solid State Ionics 146 (2002) 239.

[20] K. Matsuda, I. Taniguchi, Kagaku Kogaku Ronbunshu, J. Power Sources 29 (2003) 232.

[21] K. Matsuda, I. Taniguchi, J. Power Sources 132 (2004) 156.

[22] M. Wakihara, Mater. Sci. Eng. R33 (2001) 109.

[23] M. Hosoya, H. Ikuta, M. Wakihara, Solid State Ionics 111 (1998) 153

[24] M. Wakihara, Li Guohua, H. Ikuta, T. Uchida, Solid State Ionics 86-88 (1996) 907.

[25] S.W. Oh, S.H. Park, J.H. Kim, Y.C. Bae, Y.K. Sun, J. Power Sources 157 (2006) 464.

[26] L.J. Fu, H. Liu, C. Li, Y.P. Wu, E. Rahm, R. Holze, H.Q. Wu, Solid State Sci. 8 (2006) 113. 